\title{
CONSUMO E OBSOLESCÊNCIA PROGRAMADA: SUSTENTABILIDADE E RESPONSABILIDADE DO FORNECEDOR
}

\section{CONSUMPTION AND SCHEDULED OBSOLESCENCE: SUPPLIER SUSTAINABILITY AND RESPONSIBILITY}

\author{
${ }^{1}$ Antônio Carlos Efing \\ ${ }^{2}$ Leonardo Lindroth de Paiva
}

\section{RESUMO}

A atual sociedade de consumo é produto do mundo globalizado e que precisa de urgente reeducação, sob pena de riscos imprevisíveis e incalculáveis serem produzidos a partir das atitudes humanas. Inobstante, não se nega a necessidade da evolução, a qual pode ser solução para combater os imbróglios produzidos pela sociedade. Diante disso, busca-se, numa análise crítica, com vistas a demonstração dos problemas que podem ser causados com o desenvolvimento imensurado, refletir sobre políticas públicas para viabilizar o desenvolvimento sustentável, além de tratar acerca da responsabilidade do fornecedor pelas violações decorrentes da obsolescência antecipada de seus produtos que agridem a sustentabilidade.

PALAVRAS-CHAVE: Consumo; Desenvolvimento; Sustentabilidade; Responsabilidade do fornecedor; Globalização.

\begin{abstract}
The current consumer society is a product of the globalized world and in need of urgent reeducation, under penalty of unpredictable and incalculable risks being produced from human attitudes. In spite of this, the need for evolution is not denied, which can be a solution to combat the imbroglios produced by society. Therefore, a critical analysis is aimed at demonstrating the problems that can be caused by the immeasured development, reflecting on public policies to enable sustainable development, as well as dealing with the responsibility of the supplier for the violations resulting from the anticipated obsolescence of its products that attack sustainability.
\end{abstract}

KEYWORDS: Consumption, Development, Sustainability, Supplier responsibility, Gobalization.

\footnotetext{
${ }^{1}$ Doutor pela Pontifícia Universidade Católica - PUC, São Paulo (Brasil). Professor titular pela Pontifícia Universidade Católica - PUC, Paraná (Brasil). E-mail: ace@eradv.com.br

${ }^{2}$ Mestrando em Direito pela Pontifícia Universidade Católica - PUC, Paraná (Brasil).

E-mail: leonardo@1phjadvocacia.com.br.
} 


\section{INTRODUÇÃO}

As preocupações e os maiores problemas com o consumo surgiram juntamente com a Revolução Industrial, momento em que superou-se a regra da produção artesanal de bens para implantar-se a produção em série, massificada. A partir de então pode-se falar em sociedade de consumo. A sociedade de consumo, entretanto, mudou muito de lá até os dias atuais, principalmente diante da globalização e do desenvolvimento tecnológico, com a melhoria na transmissão de informações e a Internet cada vez mais presente.

Tais mudanças aceleraram a produção e tornaram o consumo não mais apenas um instrumento para satisfazer o necessário, mas como objeto de desejo. Consumir passou a ser demonstração de status, de classe social, de poder. E a indústria, que só tem a ganhar (financeiramente) com isso, passa a incentivar e impulsionar o consumo, a criar o desejo nos consumidores e a produzir de forma desmedida, cada vez mais, desencadeando num problema socioambiental: o consumismo.

Consumir de forma inconsciente traz prejuízos ao meio ambiente e sociedade e, por isso, o consumo inconsciente deve ser combatido.

No curso do presente estudo, trazem-se informações sobre o pós consumo, que consiste na descartabilidade dos bens e em dados sobre os resíduos e o descarte de lixo, buscando-se, na sequência opções interessantes para o consumidor e também para o fornecedor. Com base no método dedutivo, procedendo-se a levantamento doutrinário e jurisprudencial, estabelece-se a análise crítica de tais dados com vistas a demonstração dos problemas que podem ser causados com o desenvolvimento imensurado.

A busca pela sustentabilidade é árdua e ainda é intensa a busca pela conscientização de toda a sociedade. Demonstra-se a logística reversa, que dentro do âmbito das relações de consumo é de extrema importância para que possa ser completo o ciclo produtivo, principalmente por meio da reciclagem e reutilização dos produtos.

Por fim, tange-se acerca da obsolescência programada nas relações de consumo, como uma prática adotada pelos fornecedores no intuito de abreviar a vida útil dos produtos, em clara prática insustentável e que visa apenas a maximização do lucro, prejudicando-se o meio ambiente e a sociedade. Analisa-se, nesse sentido, a responsabilidade civil do fornecedor que pratica a obsolescência programada. 


\title{
1. CONSUMO E CONSUMISMO
}

Apesar de se poder falar em uma certa forma de consumo desde os tempos mais remotos, como nas sociedades que ainda se valiam do trabalho artesanal/manual, pode-se estabelecer como marco do consumo que conhecemos hoje, a Revolução Industrial.

Isso, pois nas sociedades mais antigas, justamente em decorrência do trabalho manual, a negociação entre o vendedor e o comprador se dava de maneira mais equilibrada, ou seja, o comprador adquiria o produto diretamente do artesão que o produziu e o utilizava de acordo com suas necessidades, ou ainda, trocava por um produto que produzisse ou serviço que desempenhasse.

No entanto, é a partir da Revolução Industrial que se pode começar a falar em consumidor e fornecedor ${ }^{3}$. Graças aos avanços por ela propiciados é que a capacidade produtiva foi imensamente aumentada, gerando a chamada produção em massa, fato que causou a cisão entre a produção e a distribuição dos produtos, as quais passaram a ser realizadas em grande escala (CAVALIERI FILHO, 2010, p. 02) e, portanto a se falar em fornecedor e consumidor. Acerca da Revolução Industrial,

\begin{abstract}
A fabricação de cada mercadoria passou a ser dividida em várias etapas, num processo conhecido como produção em série. Concentrado em uma única atividade, o trabalhador especializava-se e aumentava a produção. Essas características acabaram influindo no custo final do produto. Com mercadorias produzidas por meios mais baratos, era possível aumentar a margem de lucro e o mercado consumidor (FIGUEIRA, 2001, p. 198).
\end{abstract}

A partir do referido marco histórico, as relações de consumo deixaram de ser pessoais e diretas, "em que não se dá importância ao fato de não se ver ou conhecer o fornecedor" (ALMEIDA, 2009, p. 02), tornando-se massificadas e impessoais.

Ocorre que da Revolução Industrial aos dias atuais, a massificação se intensificou e o consumo evoluiu significativamente, principalmente diante de uma sociedade capitalista, incentivadora do consumo, bem como diante do desenvolvimento tecnológico e científico. Com isso, o transporte mais rápido de pessoas e produtos, as informações e comunicações instantâneas, a globalização e uma maior facilidade no

${ }^{3}$ Perceba-se que quando se falou em consumo na antiguidade, não foram utilizados os termos "consumidor" e "fornecedor", mas sim "comprador" e "vendedor", justamente por conta da diferença que passará a se expor. 
acesso aos bens de consumo, somados a uma produção em grande escala, houve redução nos custos e, consequentemente, redução nos preços dos produtos, fato que ensejou uma facilidade de aquisição dos bens. Nesse sentido,

\footnotetext{
A sociedade de consumo nasce após as demandas da Revolução Industrial, mas vai se desenvolver com as características básicas atuais, propriamente, após a Segunda Guerra Mundial e se consolidará somente a partir da década de 70, predominantemente sob o regime capitalista (GREGORI, 2010).
}

GREGORI (2010) subdivide o comportamento do consumidor em quatro fases. A primeira delas, de 1880 até a Segunda Guerra Mundial, com a produção e consumo em massa, invenção do marketing e conceito moderno de consumidor, na qual iniciou-se o consumo por mero lazer; a segunda fase, a partir de 1950, cujo progresso da sociedade e sua felicidade seriam pautados no consumo, em função dos objetos, num comportamento baseado pelo desejo de ter, antes mesmo do desejo de ser; A terceira etapa, consistente no que a autora chamou de hiperconsumo, pautava-se no consumo por impulso, sem consciência e, principalmente, pelo desperdício; A quarta e última etapa, a partir do século XXI, constitui, segundo a autora, um período de consumidores e fornecedores mais responsáveis, de consumidores mais exigentes quanto aos seus direitos, menos influenciáveis e consciente quanto ao meio ambiente e aos seus gastos. Contudo entendese que as divisões apresentadas pela autora são quanto às ideologias do consumo. Isso, pois ainda que haja, no atual momento, uma grande preocupação ambiental e a ideia de um consumo consciente, na prática não é bem isso que se vê. Ou seja, o comportamento do consumidor, em geral e notadamente no Brasil, ainda está muito relacionado à terceira fase, apesar da ideologia deste século XXI buscar severas modificações, no intuito de preservar-se a sociedade e o meio ambiente.

É diante desse comportamento padronizado que a sociedade de consumo, através de suas políticas de incentivo de consumo descomedido que acabamos presenciando resultados desastrosos como, por exemplo, o esgotamento de recursos naturais e despejos de resíduos na natureza.

Entende-se como consumo a atividade econômica que tem como objeto a obtenção e utilização de bens e serviços, buscando-se a satisfação das necessidades humanas, sejam elas essenciais ou não. Por sua vez, Zygmunt BAUMAN define o consumo como 
Una condición permanente e inamovible de la vida y um aspecto inalienable de ésta, y no está atado ni a la época ni a la historia. Desde ese punto de vista, se trata de una función imprescindible para la supervivencia biológica que nosotros, los seres humanos, compartimos con el resto de los seres vivos, y sus raíces son tan antiguas como la vicia misma. No hay dudas de que consumir es una parte integral y permanente de todas las formas de vida que conocemos, ya sea por los relatos históricos o por los informes etnográficos (BAUMAN, 2008, p. 34).

O que se verifica é que o consumo é uma prática natural e inerente ao ser humano em seus mais diversos aspectos, uma vez que é a partir da realização desse instituto que se suprem os anseios dos indivíduos, isso de modo mais simples ou complexo, haja vista a atemporalidade de tal atividade.

Todavia, é importante pontificar que dentro da sociedade de consumo estão inseridos o "consumo" e o "consumismo", questões distintas e que não devem, em nenhuma hipótese ser confundidos.

O consumismo se verifica quando o consumo é praticado em demasia, desnecessariamente e compulsivamente. Nesse sentido, BARBOSA observa:

As necessidades dos consumidores são ilimitadas e insaciáveis. Na cultura do consumidor as necessidades de cada um de nós são insaciáveis. Esta sensação de insaciabilidade é interpretada de duas formas distintas. A primeira vê como consequência da sofisticação, do refinamento, da imaginação e da personalização dos desejos e necessidades das pessoas e/ou da vontade individual do progresso econômico e social. A segunda, como uma exigência do sistema capitalista para a sua sobrevivência. A necessidade deste por um crescimento permanente cria uma ansiedade acerca da possibilidade de algum dia essas necessidades serem satisfeitas ou financiadas. (BARBOSA, 2008, p. $34)$.

A despeito do consumismo, Bauman assinala:

Se puede decir que el "consumismo" es un tipo de acuerdo social que resulta de la reconversión de los deseos, ganas o anhelos humanos (si se quiere "neutrales" respecto del sistema) en la principal fuerza de impulso y de operaciones de la sociedad, una fuerza que coordina la reproducción sistémica, la integración social, la estratificación social y la formación del individuo humano, así como también desempeña un papel preponderante en los procesos individuales y grupales de autoidentificación, y en la selección y consecución de políticas de vida individuales. El "consumismo" llega cuando el consumo desplaza al trabajo de ese rol axial que cumplía en la sociedad de productores. Mary Douglas insiste: "mientras no sepamos por qué y para qué la gente necesita lujos [vale decir, bienes más allá de los indispensables para la supervivencia] no estaremos tratando los problemas de la desigualdad ni remotamente en serio". J A diferencia del consumo, que es fundamentalmente un rasgo y una ocupación del individuo humano, el consumismo es un atributo de la sociedad. Para que una sociedad sea merecedora de ese atributo, la capacidad esencialmente individual de querer, desear y anhelar debe ser 
separada ("alienada") de los individuos (como lo fue la capacidad de trabajo en la sociedad de productores) y debe ser reciclacla/reificada como fuerza externa capaz de poner en movimiento a la "sociedad de consumidores" y mantener su rumbo en tanto forma específica de la comunidad humana, estableciendo al mismo tiempo los parámetros específicos de estrategias de vida específicas y así manipular de otra manera las probabilidades de elecciones y conductas individuales. Todo esto sigue sin decir mucho acerca del contenido de la "revolución consumista". Debemos enfocar nuestra atención en eso que "queremos", "deseamos" y "anhelamos", y en cómo la esencia de nuestras ganas, nuestros deseos y aspiraciones va cambiando como consecuencia clel pasaje hacia el consumismo (BAUMAN, 2008, p. 47).

Nesse momento, a alteração comportamental se dá porque o mercado passa investir não somente naquilo que lhe interessa vender, mas sim em meios de atrair aqueles que irão comprar.

O mercado funciona da seguinte forma: a base tecnológica e industrial produzia mercadorias, enquanto que a sociedade transformada em mercado de consumo absorvia a produção. Até que, em 1929, deu-se a crise do sistema capitalista: a crise da superprodução. A produção era tamanha que a demanda não conseguia absorvê-la, provocando o excesso da oferta frente à procura, ocasionando uma absurda queda dos preços e, consequentemente, dos lucros da burguesia. Para sua manutenção e sobrevivência, o sistema econômico necessitava demais consumidores e de mais consumo, e é nisso que se passará a investir. A indústria investirá não somente na produção de mercadorias, mas na produção da própria demanda. (GONÇALVES, 2008, p. 22)

Desta feita, é através do desenvolvimento da cultura em massa que se desenvolve meios persuasivos que incentivam ao consumo exacerbado e esse trabalho de coerção psicológica para o consumo é realizado, notadamente, pela indústria cultural através da publicidade (GONÇALVES, 2008, p. 22), a qual propaga uma necessidade insaciável de consumir.

Nesse contexto, verifica-se que consumismo representa o exagero no consumo, transformando-se em uma necessidade dos consumidores da atual sociedade capitalista, hiperconsumista, na qual "consumir é preciso", independentemente das consequências que tal ato possa trazer, de modo que consumir é uma necessidade primeira, deixando para segundo plano a responsabilidade social e ambiental (PEREIRA, 2011).

O que diferencia o consumo do consumismo é que o primeiro inerente ao ser humano e necessário na nossa sociedade. É impossível passar um dia sequer sem praticálo, pois o simples fato de utilizar a energia elétrica e água potável, por exemplo, já o caracterizam. O consumo, portanto, é necessário e não implica em qualquer problema, desde que realizado conscientemente. Já o consumismo consiste num problema 
socioambiental, capaz de destruir o meio ambiente e trazer distúrbios sociais. Nesse sentido, é necessário pautar-se num consumo moderado, observando o necessário desenvolvimento, mas antes de tudo a preservação ambiental.

\section{PÓS-CONSUMO}

A evolução histórica alterou consideravelmente as relações de consumo, de modo que o aumento da competividade, a influência da tecnologia e da globalização vêm causando considerável impacto nas configurações do mercado e na sociedade como um todo.

Um dos problemas decorrentes dessas mudanças diz respeito ao aumento da quantidade de resíduos advindos do consumo, principalmente nos grandes centros urbanos, onde criou-se uma grande problemática, originando a necessidade da destinação ambientalmente adequada dos resíduos para atingir o desenvolvimento sustentado (RABELO, 2012, p. 68).

No que tange à responsabilidade ambiental no pós consumo, verifica-se que

diz respeito à extensão do âmbito da responsabilidade civil ambiental visando à prevenção e reparação de danos ambientais causados pelos resultados de um dado processo produtivo que já tenham deixado à esfera do produtor ou fabricante por sua assimilação como produtos pelo mercado de consumo (e subsequente descarte pelo consumidor). Trata-se, portanto, de fazer com que a responsabilidade do fabricante abranja todo o ciclo de vida do produto, desde a origem, ao longo de sua cadeia de produção, até a destinação final apropriada dos resíduos gerados pela atividade - neste caso o produto regularmente consumido/utilizado -, descartados no meio ambiente. Na qualidade de geradores dos resíduos equiparam-se aos produtores e fabricantes os importadores, posto serem eles os introdutores do produto estrangeiro no mercado nacional (BALASSIANO, 2010, p. 02).

Sob esse diapasão, verifica-se que consumismo - que é a base do sistema capitalista - vem causando grandes impactos no meio ambiente, uma vez que esse sistema se sustenta pela ideia de bem-estar através da capacidade aquisitiva do indivíduo, no qual se pode (deve) consumir para obter prestigio social.

Inegáveis as facilidades que os avanços tecnológicos e da produção massificada acarretam no que diz respeito à facilidade promovida por novos produtos advindos da expansão das indústrias e do desenvolvimento tecnológico (DIAS; FILHO, 2006, p. 12), 
todavia, não se pode desconsiderar os efeitos ambientais promovidos por tal desenvolvimento.

A evolução do modelo capitalista trouxe consigo a superprodução de bens descartáveis, que são aqueles consumidos por serem cômodos aos usuários, de modo que quando não são mais uteis ou deixam de objetos de desejo são simplesmente desagregados da realidade do indivíduo e sem a menor preocupação de como se dará esse descarte.

Ao contextualizar essa realidade com a obsolescência programada (EFING; PAIVA, 2016), verifica-se que a dimensão do problema do descarte de resíduos advindos da sociedade de consumo não recebe a devida atenção das autoridades públicas, de modo que, em breve, será uma agravante na condição ambiental do planeta, haja vista o crescimento desenfreado de produção e de consumo nos países em desenvolvimento (DIAS; FILHO, 2006, p.11). Como consequência, os aterros sanitários passam a receber diariamente quantidades absurdas de resíduos sólidos urbanos (RSU).

Em pesquisa recente, a Associação Brasileira de Empresas de Limpeza Pública e Resíduos Especiais (ABRELPE) elaborou um relatório que traça o Panorama dos Resíduos Sólidos no Brasil, o qual traz dados alarmantes sobre a realidade da produção de lixo e de sua destinação (ABRELPE, 2014).

Segundo os dados apresentados no Panorama, a geração total de resíduos sólidos urbanos (RSU) no Brasil em 2014 foi de aproximadamente 78,6 milhões de toneladas, o que representa um aumento de $2,9 \%$ de um ano para outro, índice superior à taxa de crescimento populacional no país no período, que foi de $0,9 \%$, de modo que em 2013 a produção de resíduos orbitou a casas dos 76.387.200 toneladas e em 2014 foi para 78.583.405 toneladas (ABRELPE, 2014, p. 18), isto é, o consumo e o descarte passaram a serem incorporados como uma prática cultural tão fortemente arraigada que seu desenvolvimento passou a ser superior do que o próprio crescimento populacional.

Não bastasse o volume de RSU no pós-consumo crescer mais do que o número daqueles que consomem, a quantidade de RSU gerada e a coletada em 2014 mostra que o país contou com um índice de cobertura de coleta de 90,6\%, levando à constatação de que pouco mais de 7 milhões de toneladas deixaram de ser coletadas no país neste ano e, consequentemente, tiveram destino impróprio (ABRELPE, 2014, p. 29), o que leva a constatar que

Os municípios brasileiros, encarregados da limpeza urbana, depararam-se com as barreiras de caráter socioeconômico, típicas de um país em 
desenvolvimento, onde faltam recursos financeiros para cobrir até mesmo os gastos básicos com o saneamento, levando-os a optar por destinar os detritos coletados em lixões localizados nas periferias de seus núcleos urbanos em áreas próximas a cursos d'água, encostas de morros, margens de estradas, provocando impactos no solo, na qualidade da água e do ar (DIAS; FILHO, 2006, p. 12).

Para agravar a situação, a verba arrecadada com a cobrança da taxa de limpeza urbana na maioria dos casos, é insuficiente para cobrir as despesas (DIAS; FILHO, 2006, p. 12), uma vez que em 2014 os municípios aplicaram, em média, $\mathrm{R} \$ 119,76$ por habitante/ano na coleta de RSU e demais serviços de limpeza urbana (ABRELPE, 2014, p. 31).

Apesar dos fatores apontados anteriormente como a má gestão pública no que diz respeito à destinação dos resíduos sólidos, não se pode deixar de levar em consideração o comportamento humano quanto ao seu papel na produção do lixo no pósconsumo, devendo este buscar o equilíbrio entre o progresso e a preservação do meio ambiente, isto é, não se deve obstar o desenvolvimento produtivo, mas

em termos ecológicos, a sustentabilidade deve ser aqui entendida como a de um recurso ou de um ecossistema que depende de um equilíbrio entre os ritmos de extração que asseguram um mínimo de renovabilidade para o recurso. A ênfase no econômico acarreta a busca de estratégias que visem à sustentabilidade do sistema econômico. Isto é, a capacidade do sistema produtivo de manter sua produtividade, apesar das possíveis perturbações, estresse ou choques a que esteja exposto. A ênfase no social visa criar as condições socioeconômicas da sustentabilidade como, por exemplo, o atendimento às necessidades básicas, melhoria no nível de instrução, minimização da exclusão social, etc. (WIENS, 2001, p. 14).

Desta feita, infere-se que há duas vias de idealização: uma que consiste na manutenção do meio ambiente ecologicamente equilibrado, conservado, preservado; e a outra que constitui a ideia do livre exercício das atividades econômicas, assim, privilegiando a congregação dos dois ideais (SCHNEIDER, 2014, p. 11).

\section{DESENVOLVIMENTO SUSTENTÁVEL}

Leonardo BOFF defende a sustentabilidade como sendo

toda ação destinada a manter as condições energéticas, informacionais, físicoquímicas que sustentam todos os seres, especialmente a Terra viva, a comunidade de vida e a vida humana, visando a sua continuidade e ainda a 
atender as necessidades da geração presente e das futuras de tal forma que o capital natural seja mantido e enriquecido em sua capacidade de regeneração, reprodução, e coevolução (BOFF, 2012).

A questão que se discute há décadas, sem que ainda se chegasse a uma solução definitiva (da qual ainda se parece estar longe) é a possibilidade de unir o desenvolvimento econômico e a proteção ao meio embiente a fim de, então, atingir a sustentabilidade (EFING; PAIVA, 2015). Entretanto, buscam-se formas viáveis em diversas frentes a fim de alcançar o fim almejado.

Uma das possibilidades de consolidar práticas sustentáveis no mercado de consumo está relacionada com a ideia da logística reversa que, normalmente, está associada com a otimização de recursos e com as funções de pós-venda e pós-consumo ou, em palavras mais simples, a logística reversa é aquela que está interligada com a reutilização de produtos e materiais.

Nas palavras de LEITE, logística reversa é

como a área da logística empresarial que planeja, opera e controla o fluxo e as informações logísticas correspondentes, do retorno dos bens de pós-venda e de pós-consumo ao ciclo de negócios ou ao ciclo produtivo, por meio dos canais de distribuições reversos, agregando-lhes valor de diversas naturezas: econômico, ecológico, legal, logístico, de imagem corporativa, entre outros (LEITE, 2005, p. 16-17).

Válido ressaltar, também, o conceito trazido por GARCIA:

Logística reversa pode ser entendida como um processo complementar à logística tradicional, pois enquanto a última tem o papel de levar produtos de sua origem dos fornecedores até os clientes intermediários ou finais, a logística reversa deve completar o ciclo, trazendo de volta os produtos já utilizados dos diferentes pontos de consumo a sua origem. No processo da logística reversa, os produtos passam por uma etapa de reciclagem e voltam novamente à cadeia até ser finalmente descartado, percorrendo o "ciclo de vida do produto". (GARCIA, 2006, p. 4)

A logística reversa é tida como um dos instrumentos de implementação da responsabilidade compartilhada pelo ciclo de vida dos produtos, viabilizando um conjunto de ações que visam a coleta e a restituição dos produtos e resíduos sólidos remanescentes ao setor empresarial, para reaproveitamento em seu ciclo ou em outros ciclos produtivos, ou outra destinação final ambientalmente adequada (ABRELPE, 2014, p. 100) e isso se justifica uma vez que 
Considerando o aumento do consumo, a globalização das economias, a criação de padronização de produtos e a diminuição do ciclo de vida dos produtos, o fluxo de mercadorias tende a atingir um volume cada vez maior. Por isso devese levar em consideração a reciclagem ou descarte apropriado dos produtos consumidos. Nos dias de hoje, as empresas que fabricam produtos que ao serem descartados de maneira incorreta trazem risco ao meio ambiente, como pilhas e baterias, agrotóxicos, ou que reciclam suas embalagens para fabricação de novo produto, como alumínio ou embalagem PET, realizam campanhas e utilizam-se da logística reversa para reutilizar os materiais reciclados em sua linha de produção e caso não seja possível a reutilização, realizar o descarte de maneira apropriada (WILLE, 2013).

O pensamento da logística reversa no pós-consumo se caracteriza segundo Souza e Pecorone de Sá, pelo

planejamento, controle e disposição final dos bens de pós-consumo, que são aqueles bens que estão no final de sua vida útil, devido ao uso. Essa vida útil pode ser prolongada se outras pessoas virem neste mesmo bem, outras utilidades o mantendo em uso por um determinado tempo, após isso esse bem é destinado à coleta de lixo urbano, podendo ser reciclado ou simplesmente depositado em aterros sanitários, causando sérios impactos ao meio ambiente (SOUZA, 2008, p. 6).

Desta forma, conclui-se que o retorno dos produtos descartados no pós-consumo à cadeia produtiva traz soluções positivas para empresas e para a sociedade, tanto nos aspectos econômicos como nos ambientais, bem como, pode-se concluir que a estratégia empresarial e a responsabilidade ambiental não estão, necessariamente, em conflito, podendo agir de forma conjunta, pelos mesmos meios, ainda que diante de fins diversos.

\section{RELAÇÃO DE CONSUMO E OBSOLESCÊNCIA PROGRAMADA}

A prática da obsolescência programada surgiu no final dos anos 1920, quando o cartel Phoebus, formado por empresas europeias e estadunidenses, resolveu reduzir, deliberadamente, o tempo de vida útil das lâmpadas que produziam, a fim de obrigar os consumidores a compra-las com mais frequência, de modo a incentivar o consumo e, por consequência, aumentar o seu lucro. A prática, inclusive, foi vista como meio de combater 
a crise de 1929, na medida em que o maior consumo estimularia a indústria, geraria mais empregos e possibilitaria, então, o crescimento econômico ${ }^{4}$.

Não se pode negar a existência da obsolescência como algo razoável e inerente aos produtos colocados no mercado de consumo, haja vista que qualquer produto já surge com uma expectativa de vida útil. Inclusive, o Código de Defesa do Consumidor (artigo 26, I e II) diferencia os produtos duráveis dos não duráveis, prevendo que os primeiros têm uma garantia legal de, no mínimo, noventa dias e os segundos de trinta dias, reconhecendo ao menos a diferença das suas vidas úteis.

Entretanto, o que se busca coibir é a prática da obsolescência na forma programada, ou seja, uma estratégia da indústria que visa abreviar a vida útil dos produtos, com o intuito de aumentar o consumo, numa lógica de "descartabilidade" que já é incutida nos produtos desde sua concepção (SILVA, 2012), em clara intenção de estimular o consumo e otimizar os lucros, ao passo que os fornecedores já saberiam qual seria o tempo de duração do produto e preparariam um substituto para colocar no mercado e, por consequência, impor aos consumidores nova aquisição.

A obsolescência programada pode ser verificada de diferentes formas, sendo a mais tradicional o simples fim da vida útil, com a completa inutilidade do produto, pela mudança na moda ou o desejo desarrazoado de ter um produto mais atual. Busca-se combater toda e qualquer forma de obsolescência programada supérflua, ou seja, a programação da indústria para que o produto se torne obsoleto por mera conveniência do fornecedor de vender mais, sem se preocupar com o dano social (aos consumidores) e ambiental, bem como diante da falta de informação.

Por outro lado, o consumo consciente deve ser estimulado, a fim de que sejam colocados no mercado de consumo produtos desenvolvidos em observância à responsabilidade socioambiental (EFING, 2011, p. 125), o que envolve, portanto, a ausência da obsolescência programada, na medida em que esta agride os direitos dos consumidores, bem como o meio ambiente.

A agressão aos direitos dos consumidores pode ser verificada com o ferimento ao princípio da durabilidade (previsto no art. $4^{\text {o, }}$ II, alínea “d”, do CDC), bem como constituída como vício oculto, passível de reclamação pelo consumidor, quando o produto

\footnotetext{
4 Obsolescência Programada: Comprar, jogar fora, comprar. Direção e Produção: Cosima Dannoritzer. Espanha: Arte France, 2010. (52 min). Disponível em: < https://www.youtube.com/watch?v=0w5T5RoCjBg >. Acesso em: 03 mar. 2016.
} 
perecer, ter seu valor diminuído ou se tornar impróprio para o consumo antes de um prazo razoável de duração e prestabilidade, que deve ser verificado de maneira casuística. Igualmente, afeta na qualidade do produto e representa a violação de deveres dos fornecedores (transparência, informação, boa-fé, colaboração, confiança, etc.) frustrando a harmonização e segurança das relações de consumo (MARQUES; BENJAMIN, MIRAGEM, 2010, p. 484).

\section{DEFEITO DE INFORMAÇÃO, VÍCIO DE DURABILIDADE E RESPONSABILIDADE DO FORNECEDOR}

A Política Nacional das Relações de Consumo estabelece como uma de suas premissas o dever de informação, que, nas palavras de EFING

\footnotetext{
Pode ser considerado a mais importante baliza norteadora das regras inerentes à Política Nacional de Relações de Consumo, devido a sua importância e grande abrangência no sistema de defesa do consumidor.

(...)

O Princípio da informação pode ser interpretado de várias formas, todas elas percucientemente alentadoras da efetivação dos interesses do consumidor, podendo configurar-se a informação de cunho educacional, no sentido de conscientização dos consumidores acerca da buscas de seus interesses, ou em relação à informação sobre produtos e serviços colocados à disposição no mercado de consumo (EFING, 2007, p. 106).
}

O direito à informação é garantido constitucionalmente (artigo $\left.5^{\circ}, \mathrm{XIV}\right)$, bem como repisado em vários dispositivos do Código de Defesa do Consumidor, como nos artigos $6^{\circ}$, III (direito básico à informação), $8^{\circ}$ e 10 (informações sobre riscos), 12 e 14 (defeitos na informação), 18 e 20 (vícios de informação), de modo que constitui um dever do fornecedor prestar a informação clara e adequada.

No caso dos produtos nos quais está inserida a obsolescência programada, verifica-se uma violação ao dever da informação, ou seja, um defeito na informação. A obsolescência programada consiste não apenas numa omissão do dever da informação, mas como uma manipulação da informação, posto que se espera um determinado tempo de vida útil do produto, porém este tempo é diminuído de modo doloso pela indústria, a fim de tornar o produto obsoleto num menor tempo.

Claudia Lima MARQUES (2007, p. 57) assevera que é dever do fornecedor manter o consumidor permanentemente informado sobre todos os aspectos da relação de 
consumo, especialmente das questões ligadas aos riscos, qualidade do produto ou qualquer outra informação relevante para sua decisão pelo consumo.

Ora, diante disso, verifica-se na obsolescência programada além de um defeito informacional, um vício de durabilidade do produto e frusta a legítima expectativa do consumidor, violando também a confiança deste.

Nesse sentido, a durabilidade do produto diz respeito ao tempo de vida útil que dele se espera. Não se pode querer estipular legamente um tempo de vida útil para cada produto disponível no mercado de consumo, bem como não se pode confundir o tempo de vida útil com as garantias legais estabelecidas pelos incisos do artigo 26 (trinta dias para produtos não duráveis e noventa dias para produtos duráveis). Também, não se confunde o tempo de vida útil esperado com a garantia contratual fornecida.

Nesse sentido, é a decisão do Superior Tribunal de Justiça no REsp 984.106/SC, relatada pelo Ministro Luis Felipe Salomão, julgada em 04 de outubro de 2012:

DIREITO DO CONSUMIDOR E PROCESSUAL CIVIL. RECURSO ESPECIAL. AÇÃO E RECONVENÇÃO. JULGAMENTO REALIZADO POR UMA ÚNICA SENTENÇA. RECURSO DE APELAÇÃO NÃO CONHECIDO EM PARTE. EXIGÊNCIA DE DUPLO PREPARO. LEGISLAÇÃO LOCAL. INCIDÊNCIA DA SÚMULA N. 280/STF. AÇÃO DE COBRANÇA AJUIZADA PELO FORNECEDOR. VÍCIO DO PRODUTO. MANIFESTAÇÃO FORA DO PRAZO DE GARANTIA. VÍCIO OCULTO RELATIVO Å FABRICAÇÃO. CONSTATAÇÃO PELAS INSTÂNCIAS ORDINÁRIAS. RESPONSABILIDADE DO FORNECEDOR. DOUTRINA E JURISPRUDÊNCIA. EXEGESE DO ART. $26, \S 3^{\circ}$, DO CDC. (...) 4. O prazo de decadência para a reclamação de defeitos surgidos no produto não se confunde com o prazo de garantia pela qualidade do produto - a qual pode ser convencional ou, em algumas situações, legal. O Código de Defesa do Consumidor não traz, exatamente, no art. 26, um prazo de garantia legal para o fornecedor responder pelos vícios do produto. Há apenas um prazo para que, tornando-se aparente o defeito, possa o consumidor reclamar a reparação, de modo que, se este realizar tal providência dentro do prazo legal de decadência, ainda é preciso saber se o fornecedor é ou não responsável pela reparação do vício. 5. Por óbvio, o fornecedor não está, ad aeternum, responsável pelos produtos colocados em circulação, mas sua responsabilidade não se limita pura e simplesmente ao prazo contratual de garantia, o qual é estipulado unilateralmente por ele próprio. Deve ser considerada para a aferição da responsabilidade do fornecedor a natureza do vício que inquinou o produto, mesmo que tenha ele se manifestado somente ao término da garantia. 6. Os prazos de garantia, sejam eles legais ou contratuais, visam a acautelar o adquirente de produtos contra defeitos relacionados ao desgaste natural da coisa, como sendo um intervalo mínimo de tempo no qual não se espera que haja deterioração do objeto. Depois desse prazo, tolera-se que, em virtude do uso ordinário do produto, algum desgaste possa mesmo surgir. Coisa diversa é o vício intrínseco do produto existente desde sempre, mas que somente veio a se manifestar depois de expirada a garantia. Nessa categoria de vício intrínseco certamente se inserem os defeitos de fabricação relativos a projeto, cálculo estrutural, resistência de materiais, entre outros, os quais, em não raras vezes, somente se tornam conhecidos depois de algum 
tempo de uso, mas que, todavia, não decorrem diretamente da fruição do bem, e sim de uma característica oculta que esteve latente até então. 7. Cuidando-se de vício aparente, é certo que o consumidor deve exigir a reparação no prazo de noventa dias, em se tratando de produtos duráveis, iniciando a contagem a partir da entrega efetiva do bem e não fluindo o citado prazo durante a garantia contratual. Porém, conforme assevera a doutrina consumerista, o Código de Defesa do Consumidor, no $\S 3^{\circ}$ do art. 26 , no que concerne à disciplina do vício oculto, adotou o critério da vida útil do bem, e não o critério da garantia, podendo o fornecedor se responsabilizar pelo vício em um espaço largo de tempo, mesmo depois de expirada a garantia contratual. 8. Com efeito, em se tratando de vício oculto não decorrente do desgaste natural gerado pela fruição ordinária do produto, mas da própria fabricação, e relativo a projeto, cálculo estrutural, resistência de materiais, entre outros, o prazo para reclamar pela reparação se inicia no momento em que ficar evidenciado o defeito, não obstante tenha isso ocorrido depois de expirado o prazo contratual de garantia, devendo ter-se sempre em vista o critério da vida útil do bem. 9. Ademais, independentemente de prazo contratual de garantia, a venda de um bem tido por durável com vida útil inferior àquela que legitimamente se esperava, além de configurar um defeito de adequação (art. 18 do CDC), evidencia uma quebra da boa-fé objetiva, que deve nortear as relações contratuais, sejam de consumo, sejam de direito comum. Constitui, em outras palavras, descumprimento do dever de informação e a não realização do próprio objeto do contrato, que era a compra de um bem cujo ciclo vital se esperava, de forma legítima e razoável, fosse mais longo. 10. Recurso especial conhecido em parte e, na extensão, não provido. 5

Conforme decisão judicial supra referida, não obstante os prazos de garantia legal e contratual, espera-se de cada produto uma determinada vida útil, a qual independe daquelas. $\mathrm{O}$ perecimento do bem antes de finda a esperada vida útil caracterizaria quebra do princípio da boa-fé objetiva, principalmente nos caso em que se discute a obsolescência programada.

A obsolescência programada pode ser enfrentada como um vício oculto do produto (EFING; PAIVA, 2016), uma vez que é inserida propositalmente no produto, a fim de que sua vida útil seja inferior à esperada, com o objetivo de movimentar o mercado de consumo e, claramente, trazer vantagem financeira à indústria produtora em prejuízo do consumidor.

Enfrentando-a, portanto, como vício oculto do produto, nele inserido de maneira intencional pelo fornecedor, que viola princípios da boa-fé, transparência e confiança. Nessa linha de raciocínio e resgatando o apontamento jurisprudencial acima colacionado, tem-se que constantando-se a obsolescência programada de um produto, o que

\footnotetext{
${ }^{5}$ Disponível, integralmente, em:

https://ww2.stj.jus.br/revistaeletronica/Abre_Documento.asp?sSeq=1182088\&sReg=200702079153\&sDa ta $=20121120 \&$ formato=PDF. Acesso em 26 set. 2016.
} 
aconteceria, por óbvio, dentro do prazo esperado de vida útil, poderia o consumidor exigir a reparação, ou seja, responsabilizar o fornecedor.

A responsabilidade objetiva foi adotada como sistema geral nas relações de consumo, de modo que qualquer dano causado pelo fornecedor ao consumidor deve ser por aquele reparado, independentemente da verificação de culpa (SIMÃO, 2009, p. 118).

Ademais, há que se mencionar a Teoria do Risco (CAVALIERI FILHO, 2010, p. 17), pela qual é imputada a responsabilidade civil e o dever de reparar ao fornecedor, quando houver dano ao consumidor, haja vista que aquele desempenha a atividade empresarial, colhendo o bônus e devendo responder pelo ônus que dela advier.

A obsolescência programada, portanto, causa prejuízos aos consumidores, haja vista que constitui vício oculto de qualidade do produto, uma vez que a prática o torna inadequado ao consumo ou lhe diminui o valor antes de esgotar a vida útil esperada. Deve-se, portanto, responsabilizar o fornecedor, de forma objetiva e nos termos do artigo 18 do Código de Defesa do Consumidor, bem como cumpre à sociedade exercer o consumo consciente, qual seja, após informada da prática da obsolescência programada, boicotar os produtos e fornecedores adeptos da prática.

\section{CONSIDERAÇÕES FINAIS}

O consumo é inerente à sociedade e tende a aumentar, com o aumento populacional e o advento das novas tecnologias.

Entretanto, na mesma velocidade ou ainda, a fim de recuperar o tempo já perdido, em velocidade superior devem ser analisadas formas de combate ao consumo desmedido e às práticas da indústria que visam tão somente o lucro, sem se preocupar com as consequências maléficas à sociedade e ao meio ambiente.

No que tange à questão ambiental, a Política Nacional de Resíduos Sólidos destaca a importância do consumo consciente e a avaliação do ciclo de vida útil dos produtos (art. $6^{\circ}$, XIII e XV) visando a proteção do meio ambiente. Assim prática da obsolescência programada também representa violação das regras de proteção do meio ambiente, pois não obstante frustrar o consumo consciente, ainda tolhe a vida útil dos produtos, causando impactos ao meio ambiente, antecipando o pós-consumo e a geração de resíduos (como por exemplo, o preocupante lixo eletrônico ou também chamado lixo tecnológico). 
Da mesma forma, são verificados os danos sociais, principalmente nas relações de consumo, de modo que a prática da obsolescência programada constitui vício oculto do produto, ensejador de reparação, diante da responsabilidade civil objetiva, regrada no Código de Defesa do Consumidor.

Por fim, a principal forma de combate às práticas insustentáveis de consumo, como, no caso, a obsolescência programada deve ocorrer por meio da própria sociedade, pela prática do consumo consciente que levaria ao boicote dos produtos, marcas e fornecedores que lançam mão ilícita prática em desrespeito à sociedade e ao meio ambiente.

\section{REFERÊNCIAS}

ABRELPE. Panorama Dos Residuos Sólidos No Brasil. 2014. Disponível em: http://www.abrelpe.org.br/Panorama/panorama2014.pdf. Acesso em 20 set. 2016.

ALMEIDA, João Batista de. A proteção jurídica do consumidor. 7. ed. rev. e atual. São Paulo: Saraiva, 2009.

BALASSIANO, Daniela Starke. Aspectos da responsabilidade civil ambiental pósconsumo no descarte de resíduos sólidos urbanos. 2010. Disponível em: http://www.pucrio.br/pibic/relatorio_resumo2006/relatorio/CCS/Dir/DIR_07_Daniela_Starke.pdf. Acesso em 18 set. 2016.

BARBOSA, Lívia. Sociedade de consumo. Rio de Janeiro: Zahar, 2008.

BAUMAN, Zygmunt. Vida para o Consumo: A transformação das pessoas em mercadoria. Rio de Janeiro: Zahar, 2008.

BOFF, Leonardo. Sustentabilidade: tentativa de definição. Disponível em: https://leonardoboff.wordpress.com/2012/01/15/sustentabilidade-tentativa-dedefinicao/. Acesso em 06 out. 2015.

CAVALIERI FILHO, Sergio. Programa de direito do consumidor. 2. ed. São Paulo: Atlas, 2010.

DIAS, Jefferson Aparecido; FILHO, Ataliba Monteiro De Moraes. Os Resíduos Sólidos e a Responsabilidade Ambiental Pós-Consumo. 2006. Disponível em: www.prsp.mpf.gov.br/marilia. Acesso em 18 set. 2016. 
EFING, Antonio Carlos; Paiva, L. L. A obsolescência programada deve ser combatida, pois agressora dos direitos dos consumidores e do meio ambiente. Trabalho apresentado no XIII Congresso Brasileiro de Direito do Consumidor, Foz do Iguaçu, 2016 (pendente de publicação http://brasilcon.org.br/xiiicongresso/pagina/teses).

EFING, Antonio Carlos. Fundamentos do direito das relações de consumo. 2. ed., 3. tir. Curitiba: Juruá, 2007.

EFING, Antônio Carlos. Fundamentos do direito das relações de consumo. 3. ed. Curitiba: Juruá, 2011.

EFING, Antonio Carlos. Paiva, L. L. Desenvolvimento Econômico e a Proteção do Meio Ambiente em Busca da Sustentabilidade. In: XXV Encontro Nacional do CONPEDI, Brasília, 2015 (pendente de publicação).

FIGUEIRA, Divalte Garcia. História. São Paulo: Ática, 2001.

GARCIA, Manuel. Logística reversa: uma alternativa para reduzir custos e criar valor. In: XIII SIMPEP, Bauru, 2006.

GONÇALVES, Sergio Campos. Cultura e sociedade de consumo: um olhar em retrospecto. InRevista - Nucleo de Produção Cientifica em Comunicação - UNAERP, Ribeirão Preto, v.5, 2008.

GREGORI, Maria Stella. O novo paradigma para um capitalismo de consumo. Revista de Direto do Consumidor. vol. 75. Ano 19. p. 247-257. São Paulo: RT. jul.-set. 2010.

LEITE, Paulo Roberto. Logistica Reversa: Meio Ambiente e Competitividade. São Paulo: Pearson Prentice Hall, 2005.

MARQUES, Claudia Lima; BENJAMIN, Antonio Herman V.; MIRAGEM, Bruno. Comentários ao Código de Defesa do Consumidor. 3. ed. São Paulo: Revista dos Tribunais, 2010.

MARQUE, Claudia Lima et alli. Manual de Direito do Consumidor. São Paulo: Revista dos Tribunais, 2007.

PEREIRA, Agostinho O. K.; CALGARO, Cleide. Relação de consumo: tempo e espaço. Revista de Direito do Consumidor. vol. 79. ano 20. p. 311-327. São Paulo: RT. jul.-set. 2011.

RABELO, Cristina Alves. A responsabilidade civil ambiental pós-consumo na destinação de resíduos sólidos. Revista de Direito Univille - RDU. Vol. 2. n. 1. p. 6878. Joinvile: Univille. 2012.

SCHNEIDER, Vanderlei. Resíduos Sólidos: Risco Ambiental e Políticas Públicas de Proteção do Meio Ambiente no Município de Passo Fundo. Dissertação (Mestrado). Caxias Do Sul, 2014. 
SILVA, Maria Beatriz Oliveira da. Obsolescência Programada e Teoria do Decrescimento Versus Direito ao Desenvolvimento e ao Consumo (Sustentáveis). Veredas do Direito. Belo Horizonte. v. 9. n. 17, p. 181-196, jan./jun. 2012.

SIMÃO, José Fernando. Fundamentos da responsabilidade civil no Código de Defesa do Consumidor. In: SILVA, Regina Beatriz Tavares da (Coord.). Responsabilidade Civil nas Relações de Consumo. São Paulo: Saraiva, 2009.

SOUZA, Cristiane Duarte de; PECORONE DE SÁ, Natália. Logística reversa de pós-consumo: Aplicação do processo em uma empresa do ramo de construção civil. Simpósio de Excelência e Gestão em Tecnologia. Rio de Janeiro, 2008.

WIENS, Carlos Henrique. Gestão de resíduos tóxicos: o caso das lâmpadas fluorescentes descartadas em quatro empresas do setor automotivo da região metropolitana de Curitiba. Dissertação (Mestrado). Porto Alegre, 2001.

WILLE, Mariana Muller. Logística Reversa: Conceitos, Legislação e Sistema de Custeio Aplicável. Revista de Administração e Ciências Contábeis. N. 8. Curitiba: Opet, 2013. 